\title{
The production of recombinant cationic $\alpha$-helical antimicrobial peptides in plant cells induces the formation of protein bodies derived from the endoplasmic reticulum
} \author{
Emilio Montesinos ${ }^{1}$ and Maria Pla ${ }^{1, *}$ \\ ${ }^{1}$ Institute for Food and Agricultural Technology (INTEA), University of Girona, Girona, Spain \\ ${ }^{2}$ Center for Research in Agricultural Genomics (CRAG), Barcelona, Spain \\ ${ }^{3}$ Fraunhofer Institute for Molecular Biology and Applied Ecology (IME), Aachen, Germany
}

Nuri Company ${ }^{1}$, Anna Nadal ${ }^{1}$, José-Luis La Paz ${ }^{2}$, Sílvia Martínez ${ }^{2}$, Stefan Rasche ${ }^{3}$, Stefan Schillberg ${ }^{3}$,

Received 22 April 2013;

accepted 9 August 2013

*Correspondence (Tel + 349724198 52;

fax +34972 4183 99;

email maria.pla@udg.edu)

Keywords: antimicrobial peptide, BP100, cationic peptide, molecular farming, protein body, transgenic plant.

\begin{abstract}
Summary
Synthetic linear antimicrobial peptides with cationic $\alpha$-helical structures, such as BP100, are valuable as novel therapeutics and preservatives. However, they tend to be toxic when expressed at high levels as recombinant peptides in plants, and they can be difficult to detect and isolate from complex plant tissues because they are strongly cationic and display low extinction coefficient and extremely limited immunogenicity. We therefore expressed BP100 with a Cterminal tag which preserved its antimicrobial activity and demonstrated significant accumulation in plant cells. We used a fluorescent tag to trace BP100 following transiently expression in Nicotiana benthamiana leaves and showed that it accumulated in large vesicles derived from the endoplasmic reticulum (ER) along with typical ER luminal proteins. Interestingly, the formation of these vesicles was induced by BP100. Similar vesicles formed in stably transformed Arabidopsis thaliana seedlings, but the recombinant peptide was toxic to the host during latter developmental stages. This was avoided by selecting active BP100 derivatives based on their low haemolytic activity even though the selected peptides remained toxic to plant cells when applied exogenously at high doses. Using this strategy, we generated transgenic rice lines producing active BP100 derivatives with a yield of up to $0.5 \%$ total soluble protein.
\end{abstract}

\section{Introduction}

Antimicrobial peptides (AMPs) are key components of innate immunity in plants and animals and are also produced by microbes in antibiosis processes (Bulet and Stocklin, 2005; Cooter et al., 2010; Degenkolb et al., 2003; Ganz, 2003; Hancock, 2001; Jack and Jung, 2000; Lay and Anderson, 2005; Ng, 2004; Raaijmakers et al., 2006; Tincu and Taylor, 2004; Toke, 2005; Zasloff, 2002). They are generally short peptides, which can have linear structures that often adopt an amphipathic $\alpha$-helical conformation that binds to the phospholipid membranes of target microbes before the hydrophobic face is inserted into the membrane bilayer (Bechinger, 2004; Boman, 2003; Brogden, 2005; Ferré et al., 2009; Huang, 2006; Marcos and Gandía, 2009; Tossi et al., 2000). This unique mode of action helps to avoid the emergence of resistance in target pathogens (Brogden, 2005; Peschel and Sahl, 2006; Yeaman and Yount, 2003; Yount and Yeaman, 2005).

Antimicrobial peptides are valuable as novel therapeutic agents (Hancock, 2001; Marcos et al., 2008; Montesinos, 2007; Moreno et al., 2006; Rajasekaran et al., 2012; Zasloff, 2002) because of their broad-spectrum activity against bacteria, fungi, viruses, parasites and tumour cells (Ajesh and Sreejith, 2009; Broekaert et al., 1997; Brogden et al., 2003; Bulet et al., 2004; Jenssen et al., 2006; Otvos, 2000; Torrent et al., 2012; Zasloff, 2002). Natural AMPs have been optimized to increase their potency against selected pathogens while protecting nontarget organisms and enhancing stability (Badosa et al., 2007; Cavallarín et al., 1998; López-García et al., 2002; Marcos et al., 2008; Monroc et al., 2006).

The synthetic CECMEL11 peptide library, a 125-member cationic $\alpha$-helical undecapeptide library designed using a combinatorial approach, contains groups of sequences with potent and selective activity against a number of bacterial and fungal phytopathogenic reporter strains (Badosa et al., 2007, 2009; Bardají, 2006). The synthetic peptide BP100 (KKLFKKILKYL-NH ${ }_{2}$ ) was found to be effective at micromolar concentrations against Xanthomonas axonopodis pv. vesicatoria in pepper, Erwinia amylovora in apple and Pseudomonas syringae pv. syringae in pear (Badosa et al., 2007). The efficacy was comparable to standard antibiotics, and BP100 is also highly biocompatible, as determined by acute oral toxicity tests in mice (Montesinos and Bardají, 2008).

Genetically modified (GM) plants with moderate resistance to pathogenic bacteria and fungi have been developed by expressing AMPs either constitutively or induced by pathogens (reviewed by Marcos et al., 2008; Montesinos, 2007). Many different recombinant proteins have been expressed in plants (Fischer et al., 2004; Hoja and Sonnewald, 2013; Twyman et al., 2003), and the applications envisaged for CECMEL11 peptides suggest that plant-based expression would be preferable, to develop plants either that are disease resistant or that express AMPs for medical and industrial applications. Large-scale chemical synthesis of peptides above around six amino acids is only economically viable for applications of very high added value. Rice is a suitable 
platform for large-scale production, and the target product can be easily stored in the kernels for a long time allowing to decouple the production and the processing step.

BP100 was recently used as a proof-of-concept to show that the constitutive expression of short cationic $\alpha$-helical synthetic peptides can have a strong negative impact on the fitness of transgenic rice plants (Nadal et al., 2012). Transformation with five sequences encoding BP100 derivatives (BP100der) resulted in a transformation efficiency more than 100-fold less efficient than a control transgene. These BP100der peptides contained endoplasmic reticulum (ER) retention motifs to prevent peptide degradation in the cytosol and minimize toxicity to the host plant. This did not affect the antimicrobial activity of the products in vitro using bacterial growth inhibition tests. However, when applied at high doses $\left(>10^{2}\right.$-fold of the minimal inhibitory concentration, MIC), the peptides exerted toxic effects such as erythrocyte lysis, leaf damage in Nicotiana benthamiana and the inhibition of rice seedling development. The extreme physicochemical properties and low immunogenicity of the recombinant peptides prevented their direct detection in GM rice, but low levels of transgene mRNA were detected and the plants were more resistant to oxidative stress and pathogens such as Dickeya chrysanthemi and Fusarium verticillioides. We speculated that BP100der toxicity was associated with constitutive transgene expression but was ameliorated by the conferred stress tolerance.

Here, we assessed the production of recombinant BP100 derivatives in transformed $N$. benthamiana and Arabidopsis thaliana plants directly, by expressing the peptides as fusions with the fluorescent marker protein DsRed. We also screened a series of BP100 derivatives elongated with sequences from natural AMPs and found that peptides with lower haemolytic activity achieved greater transformation efficiency. We were therefore able to confirm that peptides with potent antimicrobial and low haemolytic activity can accumulate in stably transformed rice plants at levels of up to $0.5 \%$ total soluble protein (TSP).

\section{Results}

\section{BP100 derivatives can be produced by transient expression in $N$. benthamiana cells}

We previously described transgenic rice plants constitutively expressing transgenes that encoded three BP100 derivatives: bp100.1, bp100.2i and bp100.2mi (Nadal et al., 2012). The synthesis of BP100der in these plants could only be confirmed indirectly, that is, by demonstrating the presence of transgene mRNA, a resistant phenotype and ultrastructural changes in the plant cell. To confirm that active cationic $\alpha$-helical antimicrobial peptides can be made to accumulate in transgenic plants, we developed a strategy based on the fusion of BP100 to the Discosoma spp. red fluorescent reporter protein DsRed (Matz et al., 1999) and the epitope tag54 sequence for the detection of recombinant proteins using the specific antibody mAb54 (Rasche et al., 2011).

Chimeric genes encoding BP100-DsRed-tag54-KDEL (hereafter described as BP100-DsRed-tag54) and a DsRed-tag54-KDEL control lacking AMP sequences (hereafter described as DsRedtag54) were placed under the control of the constitutive Cauliflower mosaic virus 355 promoter for constitutive expression and product accumulation in the ER. The constructs were agroinfiltrated into $N$. benthamiana leaves together with HC-Pro silencing suppressor, and the accumulation of each recombinant protein was monitored by tracking the DsRed fluorescence by confocal microscopy. Three days postinfiltration (dpi), epidermal cells from $N$. benthamiana leaves transformed with the AMP and control constructs were both found to produce strong DsRed fluorescence signals in three agroinfiltrated fields representing the upper, medial and basal portions of different leaves. Cells expressing the BP100-DsRed-tag54 and DsRed-tag54 constructs had fluorescence intensities of $1004 \pm 574$ and $817 \pm 189$ fluorescence units per field, respectively, representing statistically similar expression levels as determined by one-way ANOVA $(P=0.395)$.

Western blot analysis using the tag54-specific monoclonal antibody revealed single bands of the anticipated sizes for DsRedtag54 (29 kDa) and BP100-DsRed-tag54 ( 33 kDa) as shown in Figure 1. This confirmed the presence of the BP100 peptide in the BP100-DsRed-tag54 fusion protein. The lack of a 29-kDa band in BP100-DsRed extracts showed that the BP100 peptide was not specifically cleaved from the fusion partner. There were no visible bands of the size expected for the tag54 alone, indicating the tag was not cleaved from the fusion protein either (data not shown). The observed differences in band intensity are likely to reflect the challenging extraction procedure for BP100 derivatives when dealing with complex matrices such as leaf samples. However, our data show clearly that BP100 derivatives can be synthesized in plants and directed to accumulate in plant cells.

\section{BP100 induces the formation of ER-derived vesicles}

The analysis of $N$. benthamiana leaves by confocal microscopy showed different patterns of fluorescence between the BP100

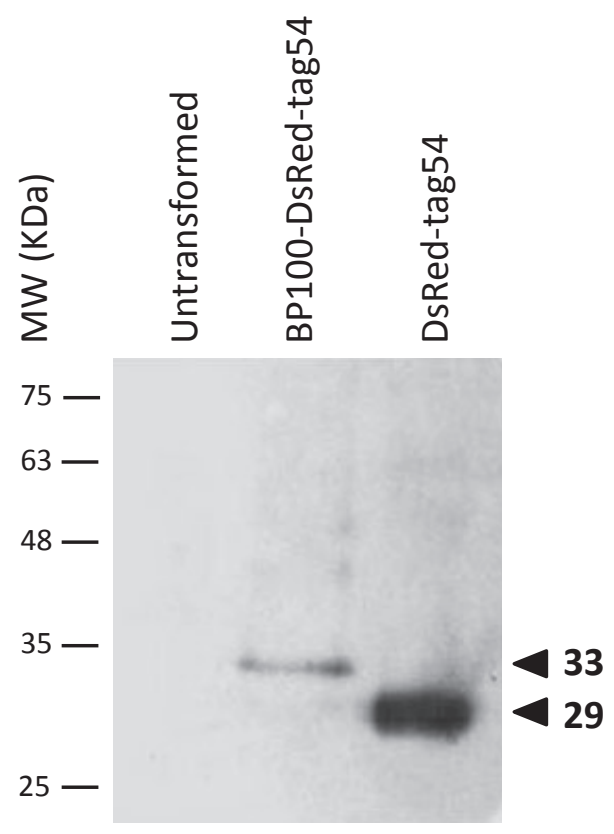

Figure 1 Transient expression of BP100-DsRed-tag54 and DsRed-tag54 in Nicotiana benthamiana leaves. Western blot of proteins extracted from $N$. benthamiana leaves agroinfiltrated with bp100-dsred-tag54 or dsredtag54 as a control. Leaf tissue was collected at $3 \mathrm{dpi}$, and $1 \mu \mathrm{g}$ of total protein was separated by SDS-PAGE before transfer to nitrocellulose filters. The recombinant proteins were detected using antibody mAb54k (diluted 1 : 1500) followed by the horseradish peroxidase-labelled antimouse IgG secondary antibody (diluted 1 : 10000) and ECL chemiluminescent detection. Arrowheads indicate BP100-DsRed-tag54 (32.9 kDa) and DsRed-tag54 control (28.5 kDa) proteins. 
and control constructs. As expected, DsRed fluorescence in the DsRed-tag54 control leaves displayed a characteristically reticulate pattern 2 days after infiltration, consistent with typical ER morphology in the plant epidermal cells. Although some cells transformed with BP100-DsRed-tag54 displayed a similar fluorescence pattern at $2 \mathrm{dpi}$, indicating that BP100 does not inhibit protein transit and retention in the ER, the majority contained numerous and widely distributed spherical structures $\sim 1-2 \mu \mathrm{m}$ in diameter showing intense fluorescence, obscuring the normal ER network. After 3-5 dpi, most cells expressing BP100-DsRedtag54 contained larger (up to $15 \mu \mathrm{m}$ ) highly fluorescent and irregular structures accompanied by smaller punctate fluorescence.

To gain insight into the origin of these structures and the integrity of the ER in cells accumulating BP100-DsRed-tag54, we co-transformed $N$. benthamiana leaves with BP100-DsRed-tag54 and another construct encoding ER-localized cyan fluorescent protein (eCFP) (Joseph et al., 2012). The merged fluorescence images in double-transformed cells at 3 dpi showed that BP100DsRed-tag54 and eCFP co-localized in the induced vesicles described above while eCFP was also visible in the ER (Figure 2a-d). This confirmed that BP100-DsRed resides transiently in the ER lumen but rapidly accumulates in novel ER-derived vesicles that contain other luminal ER proteins such as eCFP. As expected, control cells co-transformed with the DsRed-tag54 and eCFP constructs showed co-localization of the proteins within the normal ER (Figure $2 \mathrm{e}-\mathrm{h}$ ). The observed changes in ER structure therefore appear to be driven by the BP100 component of the BP100-DsRed-tag54 fusion protein.

Stably transformed Arabidopsis thaliana seedlings accumulate BP100-DsRed-tag54 in vesicles but fail to develop into mature plants

Having confirmed the accumulation of BP100-DsRed-tag54 in large ER-derived vesicles following transient expression in plant cells, we set out to determine whether this could also be achieved in A. thaliana plants stably transformed with the same constructs using the floral dip method. Two weeks after in vitro germination, the radicles of hygromycin-resistant seedlings expressing the BP100 and control constructs were analysed by confocal microscopy. All analysed transgenic plants displayed red fluorescence, and those expressing BP100-DsRed-tag54 revealed fluorescent spots $1-10 \mu \mathrm{m}$ in diameter, ranging from $1-3 \mu \mathrm{m}$ in root tip cells to $2-10 \mu \mathrm{m}$ in elongating epidermal and lateral root cells (Figure 3a,d). The morphology and distribution of the fluorescent vesicles were similar to the pattern observed in $N$. benthamiana epithelial cells.

Although we were able to recover fertile transgenic seeds producing each of the constructs, most of the seedlings expressing BP100-DsRed-tag54 did not survive acclimation, whereas those expressing the control construct developed normally. This emphasized that BP100 is phytotoxic at high concentrations even when it accumulates in vesicles. We further investigated BP100DsRed-tag54 toxicity by incubating the transgenic radicles with SYTOX, a nucleic acid stain that can only cross damaged cell membranes. We found that DsRed and SYTOX were not co-localized at this developmental stage (Figure 3). Most of the cells expressing BP100-DsRed-tag54 and the control construct DsRed-tag54 were viable, and only a few epidermal cells above the lateral root cap revealed both SYTOX and DsRed fluorescence, and the distribution of SYTOX staining was similar in wildtype $A$. thaliana cells (data not shown), suggesting the cell damage reflected normal physiological processes rather than a BP100-specific effect (Truernit and Haseloff, 2008).

Haemolytic activity can be used to predict the feasibility of constitutive BP100 expression in stably transformed plants

To improve the accumulation of BP100 derivatives (BP100der) in transgenic plants, we screened a recently described synthetic
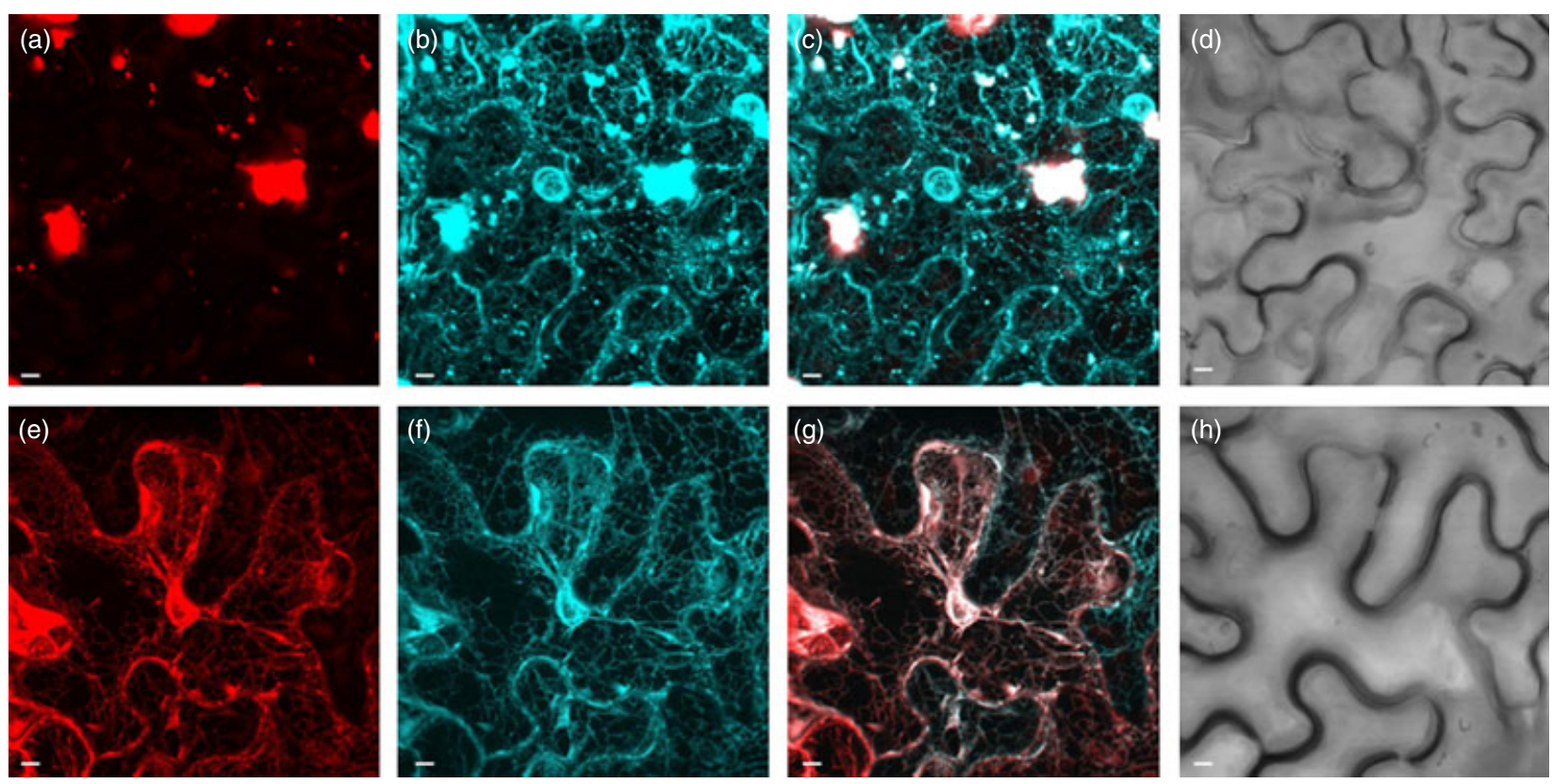

Figure 2 Confocal micrographs of Nicotiana benthamiana epidermal cells transiently expressing BP100der-DsRed-tag54 or the control DsRed-tag54. Nicotiana benthamiana leaves were co-transformed with constructs encoding ER-targeted eCFP and BP100-DsRed-tag54 (a-d) or DsRed-tag54 (e-h). (a,d), DsRed red fluorescence; $(b, f)$ eCFP cyan fluorescence; $(c, g)$, cyan and red merged images showing co-localization in white; (d,h), bright field. Scale bars, $5 \mu \mathrm{m}$. 

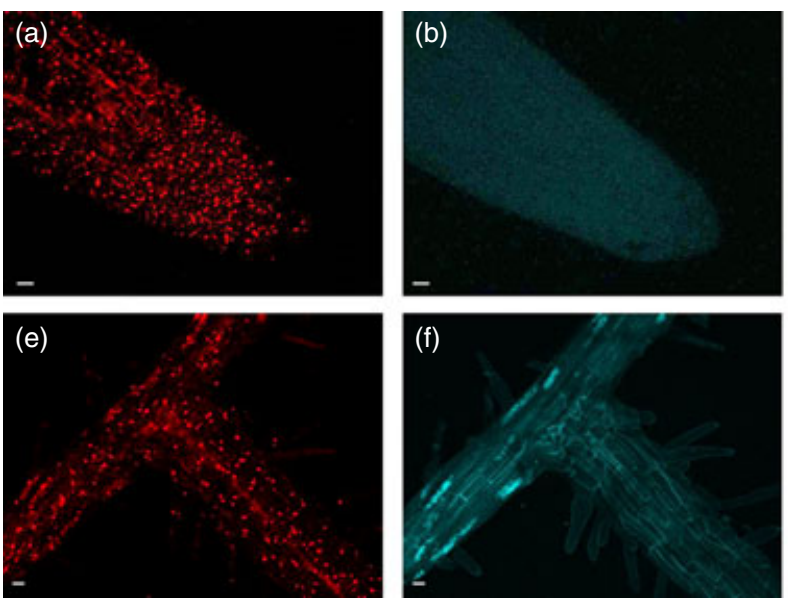
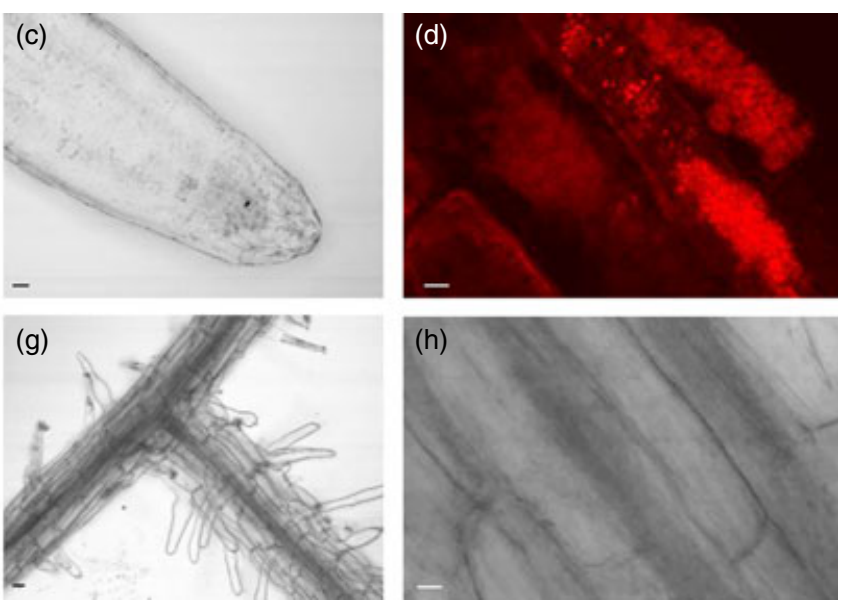

Figure 3 Confocal micrographs of transgenic Arabidopsis thaliana radicles expressing BP100-DsRed-tag54. Arabidopsis thaliana seeds obtained by floral dip transformation with recombinant bacteria carrying the BP100-DsRed-tag54 (a-c and e-g) or the DsRed-tag54 (d,h) constructs were germinated in vitro for a total of 16 days and observed by confocal microscopy following SYTOX staining. (a-c), radicle tip; (d-h), lateral root. (a,d,e), DsRed fluorescence; (b,f), SYTOX fluorescence; (c,g,h) bright field. Scale bars, $5 \mu \mathrm{m}(\mathrm{d}, \mathrm{h}), 10 \mu \mathrm{m}(\mathrm{a}-\mathrm{c})$ and $20 \mu \mathrm{m}(\mathrm{e}-\mathrm{g})$.

library of BP100 derivatives to identify less phytotoxic peptides that maintained their potent antimicrobial activity (Badosa et al., in preparation). The synthetic library of 40 BP100 derivatives included 20 carrying a C-terminal KDEL ER retention signal, and their haemolytic activity at $150 \mu \mathrm{m}$ ranged from 0 to $100 \%$. Because haemolytic activity has been widely used to determine the toxicity of peptides towards eukaryotic cells, we used this property as a tentative predictor of phytotoxicity and, by extension, of transformation efficiency in plants.

We therefore selected four BP100 derivatives with potent antimicrobial activity but the lowest haemolytic activity: BP100.m (15\%), BP100.g (4\%), BP100.g2 (4\%) and BP100.C (1\%), as shown in Table 1. All four peptides also showed stronger activity against the model plant pathogen Xanthomonas axonopodis pv. vesicatoria (Xav) than the original BP100 based on in vitro growth inhibition assays, and their activities against Erwinia amylovora (Ea) and Pseudomonas syringae pv. syringae (Pss) were similar to BP100. The modifications involved elongation with sequences derived from natural AMPs: mellitin in BP100.m, magainin in BP100.g and BP100.g2, and cecropine A in BP100.c. We also produced the additional construct BP100.gtag, which was equivalent to BP100.g but contained three copies of the tag54 epitope (tag54×3) at the C-terminal end. This reduced the haemolytic activity of the peptide to $0 \%$ at $150 \mu \mathrm{m}$ and increased its antimicrobial potency, even though the tag sequence alone had no antimicrobial activity (Table 1).

Constructs encoding the five BP100 derivatives (BP100.m, BP100.g, BP100.gtag, BP100.g2 and BP100.C, all including a C-terminal KDEL ER retention sequence) were introduced in-frame with the sequence encoding the $N$. tabacum pathogenesis-related protein PR1a signal peptide, under the control of the ubi constitutive promoter and nos terminator. All constructs were introduced in Agrobacterium tumefaciens and used to transform rice plants along with the hptll marker for hygromycin selection. Each construct yielded hygromycin-resistant plants, most of which were shown to contain the BP100der transgene by testing leaf genomic DNA by PCR (data not shown). The number of transgenic events achieved with the BP100der constructs was approximately $35-50 \%$ of the number achieved using the selectable marker alone, specifically $48 \%$ for BP100.g and BP100.gtag, $41 \%$ for BP100.m, 36\% for BP100.g2 and 34\% for BP100.C, much better than reported for other BP100 derivatives in the same expression cassette introduced as well into rice using the same method (Nadal et al., 2012).

Table 1 Sequence, and antibacterial and haemolytic activity of selected BP100 derivatives

\begin{tabular}{|c|c|c|c|c|c|}
\hline \multirow[b]{2}{*}{ AMP code } & \multirow[b]{2}{*}{ Sequence } & \multicolumn{3}{|l|}{ MIC ( $\mu \mathrm{M})$} & \multirow{2}{*}{$\begin{array}{l}\text { Haemolytic activity vs. } \\
\text { BP100 (150 } \mu \mathrm{m})\end{array}$} \\
\hline & & Xav & Pss & Ea & \\
\hline BP100 & KKLFKKILKYL & $5-10$ & $2.5-5$ & $2.5-5$ & $22.0 \pm 2.8$ \\
\hline BP100.m & KKLFKKILKYL AGPA TTGLPALISW KDEL & $5-7.5$ & $2.5-5$ & $5-7.5$ & 0.7 \\
\hline BP100.g & KKLFKKILKYL AGPA KFLHSAK KDEL & $5-7.5$ & $7.5-10$ & $2.5-5$ & 0.2 \\
\hline BP100.gtag & KKLFKKILKYL AGPA KFLHSAK AGPA KDWEHLKDWEHLKDWEHL KDEL & $2.5-5$ & $2.5-5$ & $2.5-5$ & 0.0 \\
\hline BP100.g2 & KKLFKKILKYL AGPA GIGKFLHSAK KDEL & $2.5-5$ & $2.5-5$ & $2.5-5$ & 0.2 \\
\hline BP100.C & KKLFKKILKYL AGPA VAVVGQATQIAK KDEL & $1.25-2.5$ & $2.5-5$ & $2.5-5$ & 0.1 \\
\hline Tag54 & KDWEHLKDWEHLKDWEHL KDEL & $>100$ & $>100$ & $>100$ & 0.0 \\
\hline
\end{tabular}

The KDEL ER retention sequence is underlined, the AGPA linker sequence is highlighted in bold, and the tag54 sequence in italics. Antibacterial activity was determined against Erwinia amylovora (Ea), Pseudomonas syringae pv. syryngae (Pss) and Xanthomonas axonopodis pv. vesicatoria (Xv) as reporter species. Minimal inhibitory concentrations (MIC) are shown in $\mu \mathrm{m}$ and were calculated with $10^{8}$ bacterial $\mathrm{CFU} / \mathrm{mL}$. Haemolytic activity is shown as the ratio between each peptide and the reference peptide BP100, calculated at $150 \mu \mathrm{M}$ and presented as a percentage value with confidence interval for $\alpha=0.05$ (Badosa et al., 2007 ). 
The transgene copy number and expression profile were assessed in three independent events representing each of the five bp100der transgenes. The ratio of bp100der and hptll DNA to the endogenous actin sequence was 0.5 , as determined by quantitative $P C R$ (qPCR) using leaf genomic DNA from $T_{0}$ plants, suggesting single-copy insertions. Transgene expression was verified by quantitative RT-PCR (RT-GPCR) in the same $T_{0}$ leaf samples, revealing that both hptll and the bp100der transgene were expressed in all events, with mRNA levels ranging from 0.01 through to 350 -fold the level of actin mRNA used for normalization (GeNorm $\mathrm{M}<0.5$ in these samples; Figure S1). The transformation efficiency and expression level of the bp100.gtag transgene were statistically similar to bp100.g lacking the tag54 sequence.

\section{BP100.gtag accumulates in stably transformed rice seedlings}

Five independent transgenic events expressing bp100.gtag (S-bp100.gtag) were selected for further analysis. qPCR characterization confirmed that all five events contained single transgene copies (Table 2). They were self-crossed to obtain homozygous $T_{2}$ lines. Transgene expression was monitored by RT-qPCR using stage V2 leaves (two-leaf stage) from plants grown under controlled-environment conditions. The level of bp100.gtag mRNA varied from 2 through to 67-fold the level of actin mRNA (Table 2).

We used the tag $54 \times 3$ sequence to measure the accumulation of the peptide in transgenic rice plants by Western blot. A 10.1-kDa band was detected in total soluble protein (TSP) extracts from one-week-old seedlings in four of five S-bp100.gtag events (Figure 4). Chemically synthesized BP100.gtag migrates at $\sim 5.7 \mathrm{kDa}$ when mixed with nontransformed rice extracts, which is commensurate with its theoretical mass, and a minor $\sim 10.1-\mathrm{kDa}$ band is visible at higher peptide concentrations. Serial dilutions of chemically synthesized BP100.gtag mixed with $20 \mu \mathrm{g}$ of nontransformed rice extracts $(0.72-0.045 \%$ of rice TSP) were used as a reference in Western blots to determine peptide yields in the transgenic plants. Accordingly, biologically produced BP100.gtag was shown to accumulate at levels up to $0.5 \%$ TSP in some events (e.g. S-bp100.gtag-11). There was also a positive correlation between the levels of bp100.gtag mRNA and the peptide detected in the different S-bp100.gtag events (Pearson correlation coefficient $=0.9$ ).
We further assessed the activity of the recombinant BP100.gtag by an in vitro bacterial growth inhibition test. E. amylovora growth was reduced in the presence of protein extracts obtained from S-bp100.gtag-11 homozygous $T_{2}$ seedlings in these assays, compared with protein extraction buffer and extracts of control seedlings harbouring the hptll selection gene. Inhibition levels were $63 \pm 8 \%$ (one-way ANOVA $P=0.000$ ) when compared with the extraction buffer and $51 \pm 7 \%$ (oneway ANOVA $P=0.000$ ) when compared with control seedlings. This demonstrated the antibacterial activity of the recombinant BP100 derivative.

\section{Ultrastructural changes in rice cells induced by the accumulation of BP100.gtag}

We investigated the ultrastructure of rice cells producing BP100.gtag by transmission electron microscopy (TEM) at stage V2. We found that the ER in S-BP100.gtag cells was morphologically distinct in the collar region (Figure 5a). Compared with nontransformed rice cells, there was some ER fragmentation and an increase in the abundance of dictyosome structures. As shown in Figure 5b, several cells also featured strongly dilated intracisternal spaces and ribosome-decorated ER-derived vesicles that were in some cases comparable to mitochondria in size. Dictyosome vesicles presented as a compact mass of vesicles in the cytosol of these cells.

The exogenous application of high doses (i.e. $50 \mu \mathrm{m}$ ) of chemically synthesized BP100.gtag also induced significant morphological changes in rice seedlings at the ultrastructural level. The ER, with swollen cisternae, was distributed in the cytosol near the cell wall. The nuclear envelope was more dilated than that of control cells, and there were numerous irregular vesicles containing electron-dense granules. No visible injury was observed in other cellular components (Figure 5c). However, in some cells, there was substantial disruption to the ER, including numerous irregular vesicles up to $1 \mu \mathrm{m}$ across, containing electron-dense granules, as well as irregular mitochondria with altered cristae (Figure 5d). Membrane invagination and plasmolysis were observed in the worst-affected cells.

\section{Discussion}

Several synthetic linear undecapeptides from the CECMEL11 library are useful leads for the development of novel antimicrobial

Table 2 Transgene copy numbers and mRNA expression in S-bp100.gtag rice

\begin{tabular}{|c|c|c|c|c|c|c|c|}
\hline \multirow[b]{2}{*}{ GMO event code } & \multicolumn{3}{|c|}{ Copy numbers per qPCR } & \multicolumn{2}{|c|}{$\begin{array}{l}\text { Normalized transgene } \\
\text { DNA levels }\end{array}$} & \multicolumn{2}{|c|}{$\begin{array}{l}\text { Normalized transgene mRNA expression } \\
\text { (RT-qPCR) }\end{array}$} \\
\hline & bp100.gtag & hptll & actin & bp100.gtag & hptll & bp100.gtag & hptll \\
\hline S-bp100.gtag-2 & $2.17 E+04$ & $1.59 E+04$ & $7.88 \mathrm{E}+04$ & 0.27 & 0.20 & $41.1 \pm 2.48$ & $83.85 \pm 11.18$ \\
\hline S-bp100.gtag-5 & $1.29 E+04$ & $2.05 E+04$ & $2.86 \mathrm{E}+04$ & 0.45 & 0.72 & $1.03 \pm 0.22$ & $101.98 \pm 7.90$ \\
\hline S-bp100.gtag-6 & $5.05 E+03$ & $4.92 E+03$ & $1.71 E+04$ & 0.30 & 0.29 & $68.82 \pm 2.28$ & $153.84 \pm 2.93$ \\
\hline S-bp100.gtag-7 & $8.96 \mathrm{E}+03$ & $6.04 \mathrm{E}+03$ & $3.27 E+04$ & 0.27 & 0.18 & $33.69 \pm 3.96$ & $81.52 \pm 15.09$ \\
\hline S-bp100.gtag-11 & $5.02 E+03$ & $5.62 \mathrm{E}+03$ & $1.68 \mathrm{E}+04$ & 0.30 & 0.33 & $66.60 \pm 10.97$ & $189.97 \pm 33.85$ \\
\hline
\end{tabular}

The transgene copy number was determined by qPCR using genomic DNA extracted from $T_{0}$ leaf tissue. Means of 10 qPCR experimental replicates are shown with relative standard deviation (RSD) values consistently below $2.5 \%$. Transgene copy numbers were normalized against $\beta$-actin. Considering that the $T_{0}$ plants are hemizygous concerning the transgene, ratios close to 0.5 indicate single transgene copies. Transgene mRNA expression was assessed by RT-qPCR and normalized against $\beta$-actin (GeNorm M values below 0.5) using RNA extracted from leaves of homozygous plants. For each line, means and SDs are shown for three biological replicates of 10 plants per biological replicate. 


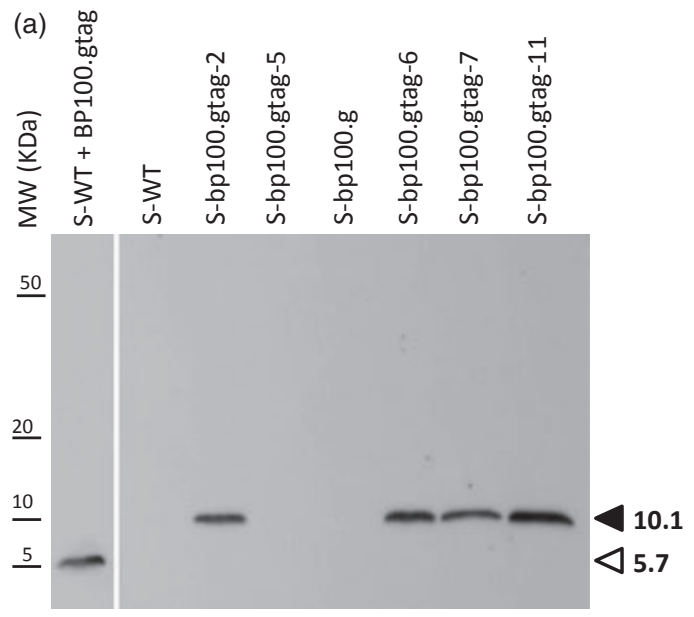

(b)

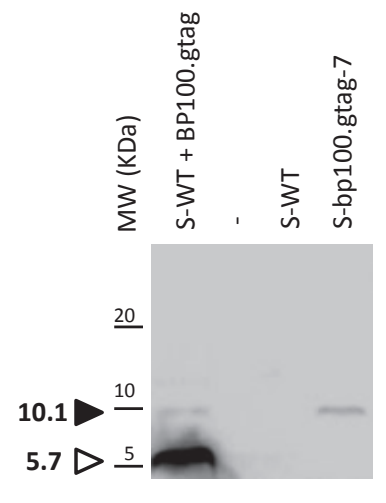

Figure 4 BP100.gtag accumulation in transgenic rice seedlings. Western blot analysis of proteins from five homozygous $T_{2} \mathrm{~S}$-bp 100.gtag rice events. Total soluble protein was extracted from rice seedling samples (five plants per event), and $20 \mu \mathrm{g}$ (a) or $4 \mu \mathrm{g}$ (b) of protein per lane was separated by SDS-PAGE before transfer to nitrocellulose filters. Recombinant proteins were detected using antibody mAb54k (diluted 1: 1500) followed by the horseradish peroxidase-labelled anti-mouse IgG secondary antibody (diluted 1 : 10000) and ECL chemiluminescent detection with $30 \mathrm{ng}$ (a) or $400 \mathrm{ng}$ (b) chemically synthesized BP100.gtag mixed with wild-type rice protein extract as a control (S-WT). S-WT and S-bp100.g (i.e. transgenic rice with the same bp100der except for the tag54 sequence) were used as additional controls. Open arrowhead indicates chemically synthesized BP100.gtag (Mw $=5.7 \mathrm{kDa})$. Closed arrowhead indicates BP100.gtag produced in transgenic plants $(\mathrm{Mw}=10.1 \mathrm{kDa})$.

agents, especially for the protection of plants against pathogens (Montesinos and Bardají, 2008; Montesinos et al., 2012). These cationic, amphipathic $\alpha$-helical peptides show potent activity against both microbial pathogens and tumour cells, but its toxicity at high concentrations towards eukaryotic cells makes them difficult to produce at high levels in plants (Nadal et al., 2012). They are also difficult to detect and isolate due to their extreme physicochemical properties (highly cationic, $\mathrm{pl}=11.5$ ), low extinction coefficient (low contents or absence of aromatic amino acids) and lack of immunogenicity as determined by in silico prediction (OptimumAntigen ${ }^{\mathrm{TM}}$ Design Tool, GenScript, NJ) and the low antibody titres observed after immunization of rabbit with a BP100-KLH conjugate (data not shown).

BP100 is a member of the CECMEL11 library with potent activity against the major bacterial pathogens of plants (Badosa et al., 2007). We expressed this peptide as a fusion with the fluorescent marker protein DsRed and the epitope tag54 to confirm that such peptides can be expressed transiently in $N$. benthamiana cells and can accumulate to similar levels as the nontoxic marker protein DsRed alone, when controlled by a strong constitutive promoter such as CaMV 355 (Piotrzkowski et al., 2012).

We also showed that targeting BP100-DsRed-tag54 to the ER using a C-terminal KDEL tag resulted in the induction and rapid accumulation of ER-derived vesicles or protein bodies (PB) that merged to form structures up to $15 \mu \mathrm{m}$ in diameter by $4 \mathrm{dpi}$. In contrast, the control protein DsRed behaved as a typical ER luminal protein, showing that the novel protein vesicles were induced by the BP100 component of BP100-DsRed-tag54. The BP100 peptide therefore appears to function in a similar manner to the highly tandemly repeated VPGXG elastin-like motif (ELP) and hydrophobins, which also induce the formation of novel ERderived protein bodies when joined to ER-targeted fusion partners (Conley et al., 2009; Joensuu et al., 2010). The 93-residue Zera polypeptide derived from the maize seed storage protein $\gamma$-zein can also induce the formation of ER-derived protein bodies although in this case the capability appears to be intrinsic and does not require an additional KDEL sequence. This property has been used to facilitate purification of the recombinant protein (Torrent et al., 2009). Fusions with peptides or polypeptides that induce vesicle formation may be suitable for hard-to-express and toxic protein candidates (Conley et al., 2011).

When we expressed an ER-targeted cyan fluorescent protein along with the DsRed constructs, this not only accumulated in the typical ER along with DsRed in the control experiments, but also co-localized with BP100-DsRed-tag54 in the novel vesicles confirming that the vesicles are derived from the ER compartment and contain typical ER-resident proteins. The proteome of ZeraDsRed protein bodies induced by transient expression in tobacco leaves has recently been characterized (Joseph et al., 2012), revealing the presence of nearly 200 additional proteins including typical ER-trafficking and ER-resident proteins that appear to be recruited to the new vesicles as if they represent extensions of the typical ER. The vesicles induced by BP100 appear to behave in a similar manner. BP100, ELP and Zera share an amphipathic structure that facilitates self-assembly (Llop-Tous et al., 2010) and membrane interactions (Alves et al., 2010). Therefore, although BP100 is much smaller and has a pl of 11.5 , its propensity for selfassembly may promote its ability to induce the formation of novel vesicles.

BP100-derived peptides are phytotoxic at concentrations 100-fold higher than the MIC for target microbes, and this was confirmed by the expression of BP100-DsRed-tag54 in stably transformed $A$. thaliana plants. Two-week-old plants demonstrated the same vesicular properties as $N$. benthamiana leaves transiently expressing the same construct, but they were unable to develop fully suggesting that long-term exposure to the peptide has a deleterious impact. Confocal micrographs of radicles expressing BP100-DsRed-tag54 and stained with SYTOX showed the same pattern of cell death as control radicles expressing DsRed alone and wild-type plants (Truernit and Haseloff, 2008). It is therefore clear that BP100 can be expressed transiently in plants without harmful effects but that long-term exposure interferes with normal growth and development. 

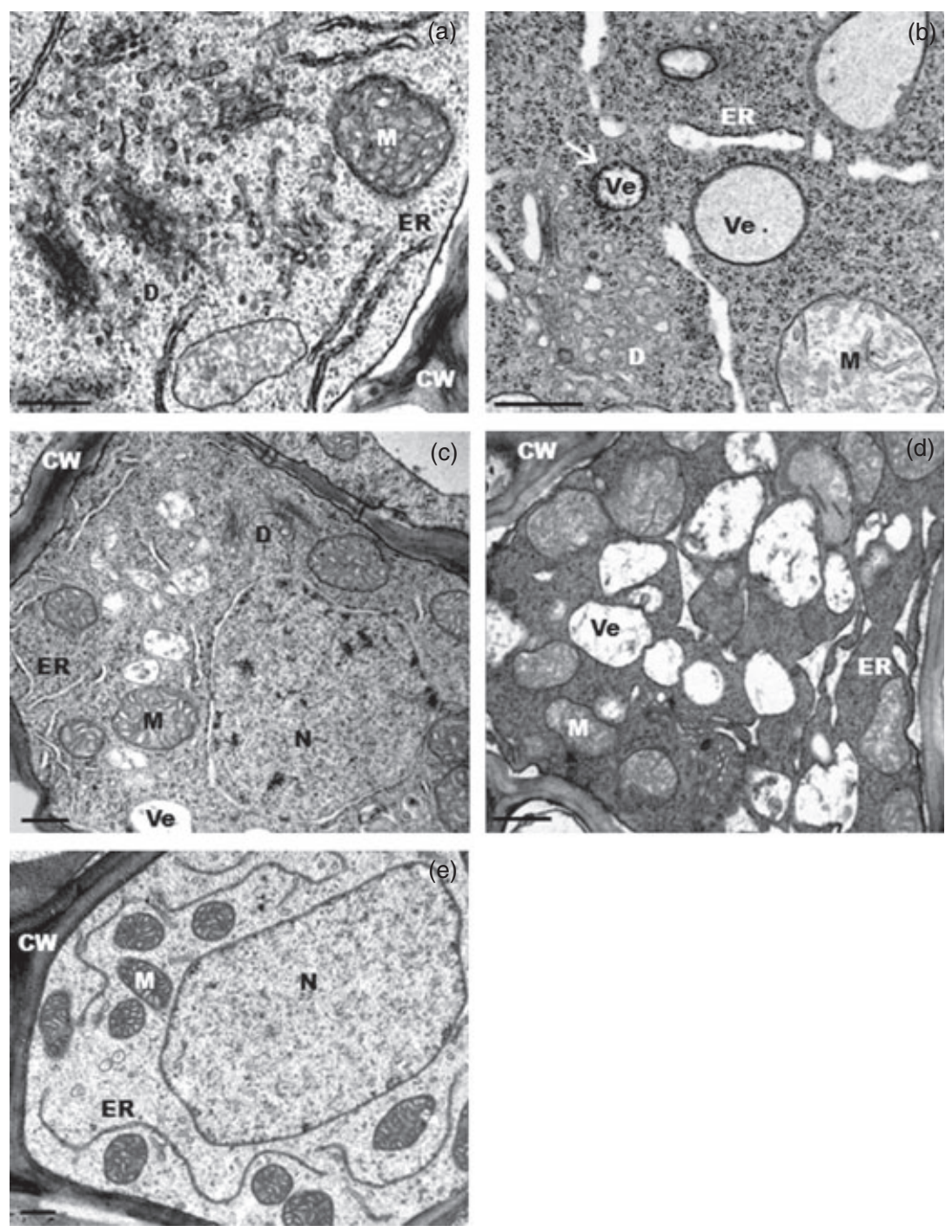

Figure 5 Transmission electron micrographs showing the effects of recombinant or exogenous BP100.gtag on the ultrastructure of rice cells. Surrounding vascular cells of the crown region of S-bp100.gtag. 11 seedlings producing BP100.gtag $(a, b)$ and untransformed rice seedlings either grown in the presence of $50 \mu \mathrm{m}$ chemically synthesized BP100.gtag for 7 days (c,d) or in control conditions (e). A, detail showing increased abundance of dictyosomes; (b), detail showing dilation of ER cisternae, ER-derived vesicles and more abundant dictyosome vesicles; (c), placement of the ER near the cell wall, with some dilation of flattened cisternae, swelling of the nuclear envelope and appearance of vesicles containing electron-dense granules; (d), altered ER morphology, numerous large vesicles with electron-dense granules, altered mitochondria. CW, cell wall; (d), dictyosome; ER, endoplasmic reticulum; $\mathrm{M}$, mitochondria; N, nucleus; Ne, nuclear envelope; Ve, vesicle; Arrow, ribosomes decorating vesicles. Scale bars, $0.5 \mu \mathrm{m}$.

The long-term toxicity of BP100 means that it is only suitable for short-term applications such as transient expression and local delivery, for example BP100 has been developed as an efficient cell-penetrating agent to deliver functional cargoes such as the actin-binding Lifeact peptide (MGVADLIKKFESISKEE) into tobacco cells (Eggenberger et al., 2011). However, longer-term applications such as stable expression in plants for molecular farming or to provide pathogen resistance in crops would benefit from rational modification to achieve a targeted reduction in phytotoxicity without affecting antimicrobial potency. We have previously noted that modified BP100 peptides (BP100der) with potent antimicrobial activity against $E$. amylovora, $X$. axonopodis pv. vesicatoria and $P$. syringae pv. syringae can vary significantly in terms of their haemolytic activity (Badosa et al., in preparation). Therefore, we hypothesized that this property could be used as a marker for phytotoxicity, allowing the selection of potent derivatives suitable for stable expression in plants based on our previous experiments in rice (Nadal et al., 2012).

We found an inverse correlation between the haemolytic activity and transformation efficiency of nine BP100der constructs, with a Pearson coefficient of -0.951 and a bilateral significance of 0.000 . One-way ANOVA distinguished two groups of sequences based on their haemolytic activity: those with haemolytic activities up to $15 \%$ at $150 \mu \mathrm{m}$ achieved transformation efficiencies of $30-50 \%$ that of the control plasmid, whereas those with haemolytic activities in the 68-99\% range at $150 \mu \mathrm{m}$ achieved only minimal transformation efficiencies (Figure 6). BP100 derivatives selected on the basis of low haemolytic activities therefore appear to provide the greatest likelihood of successful expression in stably transformed plants.

Five BP100 derivatives with low haemolytic activities were expressed in stably transformed rice, including an epitope tag to 


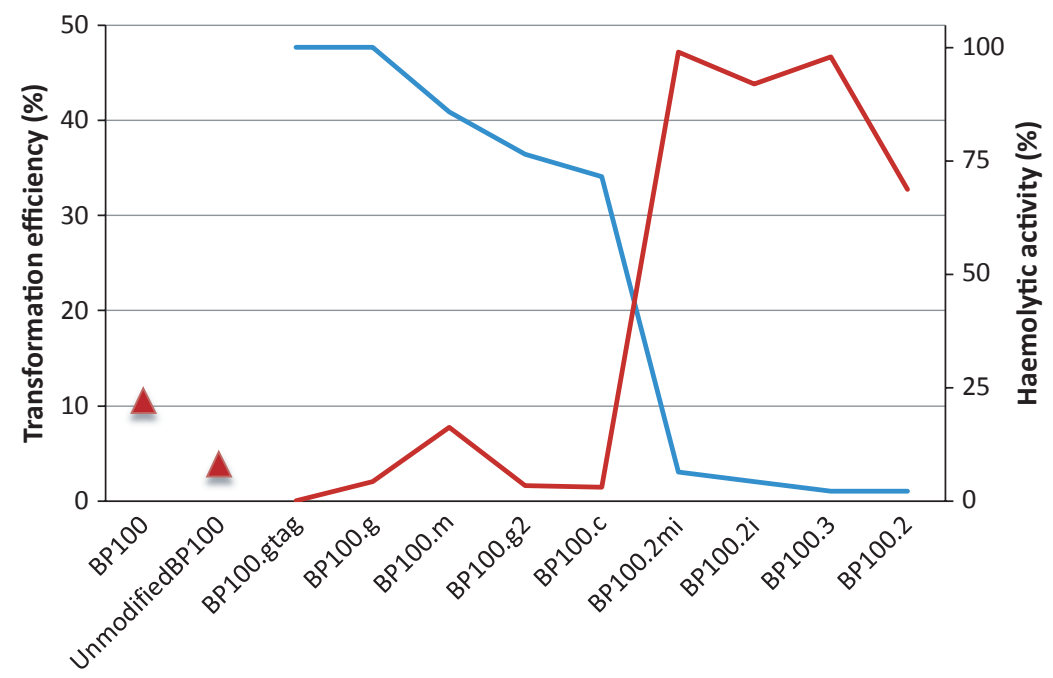

Figure 6 Haemolytic activity of BP100 derivatives and corresponding transformation efficiencies. Transformation efficiency is expressed as a percentage compared to the empty vector (hptll, blue line). Haemolytic activity is expressed as a percentage at $150 \mu \mathrm{m}$ peptide (red line). Triangles represent BP100 (amidated) and unmodified BP100, for which no transformation efficiency data are available.

facilitate detection. A direct comparison of BP100.g and BP100.gtag confirmed that the tag did not affect the antimicrobial profile or transformation efficiency of the peptide. Although the expression levels varied considerably among independent transformants with the same construct, we found a good correlation between transgene mRNA and recombinant BP100.gtag peptide levels in extracts from the transgenic plants and that the best performing lines produced up to $0.5 \%$ BP100der as a proportion of TSP and, importantly, had antibacterial activity. Similar yields of recombinant proteins have been reported using constitutive promoters in Triticum aestivum and N. tabacum (Khan et al., 2012). We cannot completely exclude the possibility that our yield estimates were affected by the unusual properties of the BP100der peptides, which result in nonspecific interactions with many components of the plant cell, thus reducing the efficiency of isolation from complex matrices. BP100 yield decreases due to unspecific adherence to plantderived molecules and surfaces of materials used during extraction and purification have been observed (L. Montesinos, personal communication). The recombinant BP100.gtag was larger than its chemically synthesized counterpart used in the control lanes (10.1 vs $5.7 \mathrm{kDa}$ ), a phenomenon that has been described for other AMPs such as Sarcotoxin IA and Cecropin A when targeted to the ER in tobacco and rice, respectively (Mitsuhara et al., 2000; Coca et al., 2006). This gain in electrophoretic mobility did not affect the activity of the peptide and may potentially reflect the proposed higher stability of these peptides as dimer.

BP100.gtag was produced in stably transformed rice plants without significantly impairing fitness, suggesting lower toxicity to the host plant than other BP100 derivatives such as BP100.2 that could not be expressed in rice plants using the same approach (Nadal et al., 2012). However, the exogenous exposure of plant tissues to high concentrations of chemically synthesized BP100.gtag did have a significant deleterious impact, as demonstrated in $N$. benthamiana leaf microinfiltration and rice seedling development assays. Indeed, all nine chemically synthesized BP100der peptides with available transformation efficiency data produced similar results in plant toxicity tests, statistical analyses (ANOVA and Tukey B post-test) clustering most peptides together
(Figure S2). There was no correlation between the $\mathrm{N}$. benthamiana leaf lesion size or inhibition of seedling development and transformation efficiency (Pearson coefficient of -0.488 and 0.586 , respectively). The assays discussed above therefore should not be relied upon to predict plant transformation efficiencies when using constitutive expression constructs and ER-targeted peptides. It may be possible to extrapolate the data obtained with BP100.gtag to other cationic $\alpha$-helical antimicrobial peptides that show some toxicity towards plant cells when applied at high concentrations.

The exogenous application of BP100.gtag to the roots of rice plants for 7 days resulted in ultrastructural changes similar to those observed in other plants exposed to heavy metals, for example modified ER and dictyosome morphology, modified nuclear envelope structure, the appearance of numerous vesicles containing electron-dense granules and in some cases the degeneration of other organelles and plasmolysis, perhaps reflecting a common response to strongly cationic molecules (Fan et al., 2011; Jiang and Liu, 2010; Liu et al., 2009). Conversely, the ultrastructure of rice cells stably transformed with bp100.gtag was less severely affected, and the dictyosome and ER modifications appeared similar to those associated with a highly active endomembrane system or the morphological changes observed during very short exposure to metal ions. The accumulation of recombinant peptides in ER-derived vesicles probably protects the cell from the worst effects, thus minimizing the residual toxicity of these BP100-derived peptides. Similarly, the antimicrobial peptide Cecropine A could be expressed in rice when targeted for accumulation in the ER but not when targeted to the apoplast (Coca et al., 2006)

In conclusion, cationic $\alpha$-helical peptides such as BP100 can be produced as recombinant proteins in plant cells, using an approach based on constitutive expression and ER targeting. Using a fluorescent fusion partner, we demonstrated that BP100 derivatives accumulate in ER-derived vesicles when transiently expressed in $N$. benthamiana and when stably expressed in A. thaliana and that the BP100 component induces the formation of these vesicles. BP100 expression in transgenic plants does not cause cell death in young tissues, but long-term expression nevertheless impairs normal growth and development. We 
demonstrated that antimicrobial peptides such as BP100 could be produced in a transient-expression plant-based platform. We also showed that BP100 derivatives with low haemolytic activity but high antimicrobial potency retain a degree of phytotoxicity at high doses but can nevertheless be produced in stably transformed rice plants at levels of up to $0.5 \%$ TSP when targeted to the ER.

\section{Experimental procedures}

\section{Chemical synthesis of BP100-derived peptides and in vitro characterization}

The BP100-derived peptides were synthesized using solid-phase Fmoc-type chemistry as previously described (Badosa et al., 2007) and assessed for purity by HPLC (the purity was $>90 \%$ in all cases). Peptide identity was confirmed by electrospray ionization mass spectrometry. Peptides were solubilized in sterile Milli-Q $\mathrm{H}_{2} \mathrm{O}$ to a concentration of $1 \mathrm{~mm}$ and filter-sterilized $(0.22-\mu \mathrm{m}$ pore filter).

Antimicrobial activity tests were carried out as previously described (Nadal et al., 2012) using the plant pathogens Erwinia amylovora PMV6076 (INRA, Angers, France), Pseudomonas syringae pv. syringae EPS94 (UdG, Girona, Spain) and Xanthomonas axonopodis pv. vesicatoria 2133-2. Positive (water instead of peptide) and negative (water instead of microbial suspension) controls were included in each experiment. Three biological replicates were performed, each comprising two experimental replicates. The lowest peptide concentration inhibiting microbial growth at the end of the experiment was established as the minimal inhibitory concentration (MIC). Haemolytic activity was assessed by measuring the release of haemoglobin from erythrocyte suspensions prepared from fresh human blood as previously described (Badosa et al., 2007). The percentage haemolysis was calculated relative to mellitin and Tris buffer. Each experiment was carried out three times.

Phytotoxic activity was determined using a rice seedling development test and a $N$. benthamiana leaf inoculation assay as previously described (Nadal et al., 2012). Toxicity in the first assay was expressed as the inverse shoot length of 12 plantlets per treatment. Toxicity in the second assay was expressed as the mean of the lesion diameters of six replicates infiltrated with $100 \mu \mathrm{l}$ of $50 \mu \mathrm{m}$ peptide.

\section{Construction of vectors}

The bp100:dsred:tag54 and dsred:tag54 constructs included the Petrosilinum hortense chalcone synthase $5^{\prime}$ untranslated region and a sequence encoding the codon optimized signal peptide from the heavy chain of monoclonal antibody 24 (Vaquero et al., 1999) upstream of BP100-DsRed or DsRed (Matz et al., 1999), and the epitope tag 12-tag54 (Rasche et al., 2011) and KDEL ER retention motif downstream, all placed under the control of the double-enhanced Cauliflower mosaic virus 355 promoter and terminator (Piotrzkowski et al., 2012). The constructs were directionally inserted into the $\mathrm{Kpnl}$ and $\mathrm{Sbfl}$ sites of pCAMBIA1300 to obtain pCbp100-dsred-tag54 and pCdsred-tag54. After sequencing the whole insert, these plasmids were transferred into A. tumefaciens strain GV2260 by electroporation and infiltrated into $N$. benthamiana leaves or used to transform $A$. thaliana plants by floral dipping. Subcloning procedures and the transformation of Escherichia coli strain XL1Blue were carried out using standard techniques (Sambrook and Russell, 2001).
Sequences encoding the five BP100 derivatives fused in-frame to the $N$. tabacum pathogenesis-related protein PR1a signal peptide sequence were designed according to rice codon usage. Synthetic bp100.c, bp100.g, bp100.g2, bp100.gtag and bp100.m genes were prepared by GenScript (Piscataway NJ) and included terminal BamHI restriction sites to facilitate insertion into pAHC17 (Oh et al., 2000). The constructs were flanked by the promoter, first exon and first intron of the maize ubiquitin-1 gene (Huang, 2000) and the $A$. tumefaciens nopaline synthase (nos) terminator. After verification by sequencing, the complete cassettes were introduced into the Kpnl site of pCAMBIA1300 in the opposite orientation to the hptll gene to generate five pCBP100der vectors for the stable transformation of rice. The resulting binary vectors were transferred into $A$. tumefaciens strain EHA105 by cold shock (Sambrook and Russell, 2001).

\section{Agroinfiltration of $N$. benthamiana leaves}

Wild-type $N$. benthamiana plants were cultivated for 4-5 weeks in a greenhouse at $18-28{ }^{\circ} \mathrm{C}$ with a long-day (16-h) photoperiod of light. And the bacteria cultures containing the expression vectors discussed above as well as the one encoding eCFP (pCSPECFPKDEL, Joseph et al., 2012; kindly provided by D. Ludevid, CRAG) were mixed with cultures carrying the HC-Pro suppressor of silencing (Goytia et al., 2006). Agroinfiltration of the abaxial side of the upper leaves was carried out using a syringe without needle.

\section{Stable transformation of $A$. thaliana}

Arabidopsis thaliana plants were transformed with $A$. tumefaciens cultures carrying the expression vectors discussed above by floral dipping (Clough and Bent, 1998). Seeds were surface-sterilized and allowed to germinate on MS medium with $20 \mathrm{mg} / \mathrm{L}$ hygromycin B in culture chambers for 3 days in the dark at $4{ }^{\circ} \mathrm{C}$ (stratification) and 13 days under long-day conditions (16-h photoperiod) at $22{ }^{\circ} \mathrm{C}$. Plantlets were analysed by confocal microscopy or allowed to grow to maturity under standard conditions.

\section{Stable transformation of rice}

Embryonic rice callus (Oryza sativa L., ssp japonica, cv Senia) derived from mature embryos as described (Pons et al., 2000) was transformed with the constructs discussed above and pCAMBIA 1300 (containing hptll) as a control. We transformed 500 callus pieces with the constructs containing the bp100.gtag, bp100.m, bp100.g and bp100.c genes and 1000 callus pieces with the constructs containing the bp100.c2 and bp100.g2 genes. Hygromycin-resistant, fertile $T_{0}$ plants were grown to maturity, and leaves were tested for transgene insertion by qPCR. The efficiency of transformation was calculated by comparing the number of transformants obtained with each BP100der construct compared with the pCAMBIA 1300 control. S-bp100.gtag plants were cultured under standard greenhouse conditions to obtain homozygous transgenic lines in the $T_{2}$ generation.

\section{Protein extraction and Western blot analysis}

Total soluble protein was extracted from three $N$. benthamiana leaf sections $\left(\sim 1 \mathrm{~cm}^{2}\right.$ agroinfiltrated tissue) or shoots from six rice seedlings germinated in a culture chamber at $25 \pm 1{ }^{\circ} \mathrm{C}$ with a photoperiod of $16 \mathrm{~h}$ light/8 $\mathrm{h}$ dark under fluorescent Sylvania Cool White lamps. Tissue was extracted in lysis buffer $(10 \mathrm{~mm}$ Tris- $\mathrm{HCl}$ pH 6.2, $50 \mathrm{~mm} \mathrm{KCl}, 6 \mathrm{~mm} \mathrm{MgCl} 2,0.4 \mathrm{M} \mathrm{NaCl}, 1 \%$ (v/v) Triton X-100 and $10 \mathrm{~mm}$ EDTA) and centrifuged at $16000 \boldsymbol{g}$ for 15 min at $4{ }^{\circ} \mathrm{C}$, and the protein concentration in the supernatant was determined using the Bradford method. The extracted 
protein was separated by $12 \%$ or $15 \%(\mathrm{w} / \mathrm{v})$ SDS polyacrylamide gel electrophoresis (20 or $4 \mu \mathrm{g}$ per lane) and transferred to nitrocellulose filters, and the tag54 epitope was detected with monoclonal antibody mAb54k (Rasche et al., 2011) diluted $1: 1500$, overnight at $4{ }^{\circ} \mathrm{C}$. Binding was detected using a horseradish peroxidase-conjugated anti-mouse $\lg G$ secondary antibody (GE Healthcare Life sciences) diluted $1: 10000$ for $1 \mathrm{~h}$ at room temperature. The signal was detected by $\mathrm{ECL}$ chemiluminescence (Supersignal ${ }^{\circledR}$ West Femto, Thermo Scientific, Waltham, MA) and quantified using Multi Gauge v3.0 software based on 25.0, 12.5, 6.25, 3.125 and 1.5625 pmol standards corresponding to $143.4-9.0 \mathrm{ng}$ of chemically synthesized BP100.gtag mixed with protein extracts from wild-type rice, or $0.72-0.045 \%$ rice TSP, run on the same gel.

\section{Antimicrobial activity of recombinant peptides}

Protein extracts were obtained from 30 rice seedlings germinated for 4 days in a culture chamber at $25 \pm 1{ }^{\circ} \mathrm{C}$ with a photoperiod of $16 \mathrm{~h}$ light/ $8 \mathrm{~h}$ dark. Tissue was ground in liquid nitrogen and treated with $10 \mathrm{~mm}$ phosphate buffer $\mathrm{pH} 7.5$ and $0.6 \mathrm{~m}$ sucrose buffer, previously sterilized through a $0.2-\mu \mathrm{m}$ pore filter. The extract was centrifuged at $200 \mathrm{~g}$ for $10 \mathrm{~min}$ at $4{ }^{\circ} \mathrm{C}$, and the supernatant was re-centrifuged at $2000 \mathrm{~g}$ for $10 \mathrm{~min}$ at $4{ }^{\circ} \mathrm{C}$ to precipitate a fraction enriched in vesicles and protein bodies, which was re-suspended in $10 \mathrm{~mm}$ phosphate buffer $\mathrm{pH} 7.5$ with protease inhibitor cocktail (Sigma-Aldrich, Munich, Germany). Protein concentrations were determined using the Bradford method and were consistently in the $12-15 \mathrm{mg} / \mathrm{mL}$ range. Preliminary experiments showed that the protein extraction buffer had no effect on E. amylovora growth, but protein extracts from control rice samples inhibited bacterial growth. Dilution of protein extracts to $1 / 3$ in the same buffer permitted growth of the indicator bacteria after a short lag phase. To evaluate the expected inhibition of the recombinant BP100.gtag, controls were carried out with extracts from rice seedlings harbouring only the hptll selection gene. Three biological replicates were performed, each comprising three experimental replicates. The area under the growth curve (AUC) was used to calculate the inhibition effects of the extracts from transgenic seedlings expressing BP100.gtag compared with control seedlings or the buffer control: (Ac-At)*100/Ac, where Ac and At are the AUC of control and test seedlings, respectively.

\section{Imaging}

\section{Confocal microscopy}

Nicotiana benthamiana leaves and $A$. thaliana leaves/radicles were analysed by confocal microscopy using an FV1000 Olympus microscope. Red fluorescence images were collected at $559 \mathrm{~nm}$ excitation and 570-670 nm emission, whereas cyan fluorescence images were collected at $405 \mathrm{~nm}$ excitation and 460-500 nm emission. ImageJ software (http://rsb.info.nih.gov/ij/) was used to calculate the number and size of fluorescent spots or aggregates. SYTOX staining was carried out by incubating plantlets with $2.5 \mu$ м SYTOX (Invitrogen Life Technologies, Carlsbad, CA) for $24 \mathrm{~h}$ prior to analysis at $559 \mathrm{~nm}$ excitation and 570-670 nm emission. A total of three agroinfiltrated fields in the upper, medial and basal portions of different leaves were analysed using Olympus Fluoview v3.1 software with standard parameters. IBM SPSS Statistics19 software was used to compare means by one-way ANOVA and Tukey B post-test.

\section{Transmission electron microscopy}

Rice seeds were allowed to germinate for 7 days in distilled water under controlled conditions, with or without $50 \mu \mathrm{m}$ chemically synthesized BP100.gtag. Sections of the collar region were excised and fixed in 1\% (v/v) glutealdehyde and $2.5 \%(\mathrm{v} / \mathrm{v})$ paraformaldehyde in $0.1 \mathrm{M}$ phosphate buffer, $\mathrm{pH} 7.4$, overnight at room temperature. TEM sections were prepared by the Service for Microscopy at the Autonomous University of Barcelona, and images were collected on a GEM-1400 TEM. Wild-type rice and plants transformed with the PCAMBIA 1300 vector (containing hptll) were used as controls.

\section{Nucleic acid extraction, qPCR and RT-qPCR}

To assess transgene copy number, genomic DNA was extracted from $1 \mathrm{~g}$ of mature hemizygous $T_{0}$ leaf tissue using a CTAB method (Coll et al., 2008) and analysed by qPCR targeting conserved sequences in each construct, with 10 experimental replicates (Nadal et al., 2012) and the rice $\beta$-actin gene as a standard for normalization (Montero et al., 2011). All oligonucleotides were purchased from MWG Biotech AG (Germany).

Transgene expression was measured in leaf samples from three independent $T_{0}$ transgenic rice plants representing each construct and in five homozygous lines expressing bp100.gtag. Leaves of the homozygous $T_{2}$ plants were sampled at the two-leaf vegetative stage, and three biological replicates of 10 plants (i.e. a total of 30 plants) were analysed per line. Total RNA was extracted from 400-mg samples using Trizol reagent (Invitrogen Life Technologies) with DNase I treatment (Ambion, Grand Island, NY), according to the manufacturer's instructions. The concentration and quality of the RNA were confirmed by UV absorption at 260 and $280 \mathrm{~nm}$ using a NanoDrop ND1000 spectrophotometer (Nanodrop technologies, Wilmington, DE). RT-qPCR was carried out as previously described (Nadal et al., 2012). For each sample, cDNA was prepared with random primers in duplicate, and the reactions were performed in triplicate. The absence of DNA targets was demonstrated using DNase-treated samples. All reactions had linearity coefficients exceeding 0.99 and efficiency values above 0.95 . The $\beta$-actin gene was used for normalization, its suitability having been confirmed using the geNORM v3.4 statistical algorithm (Vandesompele et al., 2002; M values below 0.5 in our samples).

\section{Acknowledgements}

This work was supported by the Spanish Ministerio de Ciencia e Innovación (projects AGL2010-17181/AGR and PLANT-KBBE EUI2008-03769) and BMBF PLANT-KBBE FKZ0315456B. We thank J. Messeguer and E. Melé (IRTA, Cabrils) for valuable suggestions; D. Ludevid (CRAG, Barcelona) for providing plasmid material; M. Amenós (CRAG) and the staff of the Microscopy Service (Universitat Autonoma de Barcelona) for technical assistance; E. Badosa and L. Montesinos for assessing the antimicrobial activity of chemically synthesized peptides; and the scientific writer R.M. Twyman for revision of the manuscript.

\section{References}

Ajesh, K. and Sreejith, K. (2009) Peptide antibiotics: an alternative and effective antimicrobial strategy to circumvent fungal infections. Peptides, 30, 999 1006 . 
Alves, C.S., Melo, M.N., Franquelim, H.G., Ferré, R., Planas, M., Feliu, L., Bardají, E., Kowalczyk, W., Andreu, D., Santos, N.C., Fernandes, M.X. and Castanho, M.A. (2010) Escherichia coli cell surface perturbation and disruption induced by antimicrobial peptides BP100 and pepR. J. Biol. Chem. 285, 27536-27544

Badosa, E., Ferré, R., Planas, M., Feliu, L., Besalú, E., Cabrefiga, J., Bardají, E. and Montesinos, E. (2007) A library of linear undecapeptides with bactericidal activity against phytopathogenic bacteria. Peptides, 28, 2276-2285.

Badosa, E., Ferre, R., Frances, J., Bardaji, E., Feliu, L., Planas, M. and Montesinos, E. (2009) Sporicidal activity of synthetic antifungal undecapeptides and control of Penicillium rot of apples. Appl. Environ. Microbiol. 75, 5563-5569.

Bardají, E. Antimicrobial linear peptides. (Patent WO/2007/125142 A1). (2006).

Bechinger, B. (2004) Structure and function of membrane-lytic peptides. Crit. Rev. Plant Sci. 23, 271-292.

Boman, H.G. (2003) Antibacterial peptides: basic facts and emerging concepts. J. Intern. Med. 254, 197-215.

Broekaert, W., Cammue, B., De Bolle, M., Thevissen, K., De Samblanx, G. and Osborn, R. (1997) Antimicrobial peptides from plants. Crit. Rev. Plant Sci. 16, 297-323.

Brogden, K.A. (2005) Antimicrobial peptides: pore formers or metabolic inhibitors in bacteria? Nat. Rev. Microbiol. 3, 238-250.

Brogden, K.A., Ackermann, M., McCray, P.B. Jr and Tack, B.F. (2003) Antimicrobial peptides in animals and their role in host defences. Int. J. Antimicrob. Agents, 22, 465-478.

Bulet, P. and Stocklin, R. (2005) Insect antimicrobial peptides: structures, properties and gene regulation. Protein Pept. Lett. 12, 3-11.

Bulet, P., Stocklin, R. and Menin, L. (2004) Anti-microbial peptides: from invertebrates to vertebrates. Immunol. Rev. 198, 169-184.

Cavallarín, L., Andreu, D. and San Segundo, B. (1998) Cecropin A-derived peptides are potent inhibitors of fungal plant pathogens. Mol. Plant Microbe Interact. 11, 218-227.

Clough, S.J. and Bent, A.F. (1998) Floral dip: a simplified method for Agrobacterium-mediated transformation of Arabidopsis thaliana. Plant $J$. 16, 735-743.

Coca, M., Peñas, G., Gómez, J., Campo, S., Bortolotti, C., Messeguer, J. and San Segundo, B. (2006) Enhanced resistance to the rice blast fungus Magnaporthe grisea conferred by expression of a cecropin A gene in transgenic rice. Planta, 223, 392-406.

Coll, A., Nadal, A., Palaudelmàs, M., Messeguer, J., Melé, E., Puigdomènech, P. and Pla, M. (2008) Lack of repeatable differential expression patterns between MON810 and comparable commercial varieties of maize. Plant Mol. Biol. 68, 105-117.

Conley, A.J., Joensuu, J.J., Menassa, R. and Brandle, J.E. (2009) Induction of protein body formation in plant leaves by elastin-like polypeptide fusions. BMC Biol. 7, 48

Conley, A.J., Joensuu, J.J., Richman, A. and Menassa, R. (2011) Protein body-inducing fusions for high-level production and purification of recombinant proteins in plants. Plant Biotechnol. J. 9, 419-433.

Cooter, P.D., Hill, C. and Ross, P. (2010) Bacterial lantibiotics: strategies to improve therapeutic potential. Curr. Prot. Pept. Sci. 6, 61-75.

Degenkolb, T., Berg, A., Gams, W., Schlegel, B. and Grafe, U. (2003) The occurrence of peptaibols and structurally related peptaibiotics in fungi and their mass spectrometric identification via diagnostic fragment ions. J. Pept. Sci. 9, 666-678.

Eggenberger, K., Mink, C., Wadhwani, P., Ulrich, A.S. and Nick, P. (2011) Using the peptide $\mathrm{Bp} 100$ as a cell-penetrating tool for the chemical engineering of actin filaments within living plant cells. ChemBioChem, 12, 132-137.

Fan, J.L., Wei, X.Z., Wan, L.C., Zhang, L.Y., Zhao, X.Q., Liu, W.Z., Hao, H.Q. and Zhang, H.Y. (2011) Disarrangement of actin filaments and $\mathrm{Ca}^{2+}$ gradient by $\mathrm{CdCl}_{2}$ alters cell wall construction in Arabidopsis thaliana root hairs by inhibiting vesicular trafficking. J. Plant Physiol. 168, 1157-1167.

Ferré, R., Melo, M.N., Correira, A.D., Feliu, L., Bardají, E., Planas, M. and Castanho, M. (2009) Synergistic effects of the membrane actions of cecropin-melittin antimicrobial hybrid peptide BP100. Biophys. J. 96, 1815-1827.

Fischer, R., Stoger, E., Schillberg, S., Christou, P. and Twyman, R.M. (2004) Plant-based production of biopharmaceuticals. Curr. Opin. Plant Biol. 7, 152158.
Ganz, T. (2003) Defensins: antimicrobial peptides of innate immunity. Nat. Rev Immunol. 3, 710-720

Goytia, E., Fernández-Calvino, L., Martínez-García, B., López-Abella, D. and López-Moya, J.J. (2006) Production of plum pox virus HC-Pro functionally active for aphid transmission in a transient-expression system. J. Gen. Virol. 87, 3413-3423.

Hancock, R.E. (2001) Cationic peptides: effectors in innate immunity and novel antimicrobials. Lancet Infect. Dis. 1, 156-164.

Hoja, U. and Sonnewald, U. (2013) Molecular Farming in Plants, Encyclopedia of Life Sciences. Chichester: John Wiley \& Sons Ltd.

Huang, H.W. (2000) Action of antimicrobial peptides: two-state model. Biochemistry, 39, 8347-8352.

Huang, H.W. (2006) Molecular mechanism of antimicrobial peptides: the origin of cooperativity. Biochim. Biophys. Acta, 1758, 1292-1302.

Jack, R.W. and Jung, G. (2000) Lantibiotics and microcins: polypeptides with unusual chemical diversity. Curr. Opin. Chem. Biol. 4, 310-317.

Jenssen, H., Hamill, P. and Hancock, R.E. (2006) Peptide antimicrobial agents. Clin. Microbiol. Rev. 19, 491-511.

Jiang, W. and Liu, D. (2010) Pb-induced cellular defense system in the root meristematic cells of Allium sativum L. BMC Plant Biol. 10, 40.

Joensuu, J.J., Conley, A.J., Lienemann, M., Brandle, J.E., Linder, M.B. and Menassa, R. (2010) Hydrophobin fusions for high-level transient protein expression and purification in Nicotiana benthamiana. Plant Physiol. 152, 622-633.

Joseph, M., Ludevid, M.D., Torrent, M., Rofidal, V., Tauzin, M., Rossignol, M. and Peltier, J.B. (2012) Proteomic characterisation of endoplasmic reticulum-derived protein bodies in tobacco leaves. BMC Plant Biol. 12, 36.

Khan, I., Twyman, R.M., Arcalis, E. and Stoger, E. (2012) Using storage organelles for the accumulation and encapsulation of recombinant proteins. Biotechnol. J. 7, 1099-1108.

Lay, F.T. and Anderson, M.A. (2005) Defensins-components of the innate immune system in plants. Curr. Protein Pept. Sci. 6, 85-101.

Liu, D., Jiang, W., Meng, Q., Zou, J., Gu, J. and Zeng, M. (2009) Cytogenetical and ultrastructural effects of copper on root meristem cells of Allium sativum L. Biocell, 33, 25-32.

Llop-Tous, I., Madurga, S., Giralt, E., Marzabal, P., Torrent, M. and Ludevid, M.D. (2010) Relevant elements of a maize gamma-zein domain involved in protein body biogenesis. J. Biol. Chem. 285, 35633-35644.

López-García, B., Pérez-Paya, E. and Marcos, J.F. (2002) Identification of novel hexapeptides bioactive against phytopathogenic fungi through screening of a synthetic peptide combinatorial library. Appl. Environ. Microbiol. 68, 24532460.

Marcos, J.F. and Gandía, M. (2009) Antimicrobial peptides: to membranes and beyond. Expert Opin. Drug Discov. 4, 659-671.

Marcos, J.F., Muñoz, A., Pérez-Paya, E., Misra, S. and López-García, B. (2008) Identification and rational design of novel antimicrobial peptides for plant protection. Annu. Rev. Phytopathol. 46, 273-301.

Matz, M.V., Fradkov, A.F., Labas, Y.A., Savitsky, A.P., Zaraisky, A.G., Markelov, M.L. and Lukyanov, S.A. (1999) Fluorescent proteins from nonbioluminescent Anthozoa species. Nat. Biotechnol. 17, 969-973.

Mitsuhara, I., Matsufuru, H., Ohshima, M., Kaku, H., Nakajima, Y., Murai, N. Natori, S. and Ohashi, Y. (2000) Induced expression of sarcotoxin IA enhanced host resistance against both bacterial and fungal pathogens in transgenic tobacco. Mol. Plant Microbe Interact. 13, 860-868.

Monroc, S., Badosa, E., Besalú, E., Planas, M., Bardají, E., Montesinos, E. and Feliu, L. (2006) Improvement of cyclic decapeptides against plant pathogenic bacteria using a combinatorial chemistry approach. Peptides, 27, 2575-2584.

Montero, M., Coll, A., Nadal, A., Messeguer, J. and Pla, M. (2011) Only half the transcriptomic differences between resistant genetically modified and conventional rice are associated with the transgene. Plant Biotechnol. J. 9, 693-702.

Montesinos, E. (2007) Antimicrobial peptides and plant disease control. FEMS Microbiol. Lett. 270, 1-11.

Montesinos, E. and Bardají, E. (2008) Synthetic antimicrobial peptides as agricultural pesticides for plant-disease control. Chem. Biodivers. 5, 1225-1237.

Montesinos, E., Badosa, E., Cabrefiga, J., Planas, M., Feliu, L. and Bardají, E. (2012) Antimicrobial peptides for plant disease control. From discovery to 
application. In Small Wonders: Peptides for Disease Control (Rajasekaran, K. Cary, J., Jaynes, J. and Montesinos, E., eds.), pp. 235-261. Washington, DC Oxford University Press.

Moreno, A.B., Martínez, D.P. and San Segundo, B. (2006) Biotechnologically relevant enzymes and proteins. Antifungal mechanism of the Aspergillus giganteus AFP against the rice blast fungus Magnaporthe grisea. Appl. Microbiol. Biotechnol. 72, 883-895.

Nadal, A., Montero, M., Company, N., Badosa, E., Messeguer, J., Montesinos, L., Montesinos, E. and Pla, M. (2012) Constitutive expression of transgenes encoding derivatives of the synthetic antimicrobial peptide BP100: impact on rice host plant fitness. BMC Plant Biol. 12, 159.

Ng, T.B. (2004) Peptides and proteins from fungi. Peptides, 25, 1055-1073.

Oh, D., Shin, S.Y., Lee, S., Kang, J.H., Kim, S.D., Ryu, P.D., Hahm, K.S. and Kim, $Y$. (2000) Role of the hinge region and the tryptophan residue in the synthetic antimicrobial peptides, cecropin A(1-8)-magainin 2(1-12) and its analogues, on their antibiotic activities and structures. Biochemistry, 39, 11855-11864

Otvos, L. Jr. (2000) Antibacterial peptides isolated from insects. J. Pept. Sci. 6, 497-511.

Peschel, A. and Sahl, H.G. (2006) The co-evolution of host cationic antimicrobial peptides and microbial resistance. Nat. Rev. Microbiol. 4, 529-536.

Piotrzkowski, N., Schillberg, S. and Rasche, S. (2012) Tackling heterogeneity: a leaf disc-based assay for the high-throughput screening of transient gene expression in tobacco. PLOS ONE, 7, e45803.

Pons, M.J., Marfà, V., Melé, E. and Messeguer, J. (2000) Regeneration and genetic transformation of Spanish rice cultivars using mature embryos. Euphytica, 114, 117-122.

Raaijmakers, J.M., De Bruijn, I. and de Kock, M.J. (2006) Cyclic lipopeptide production by plant-associated Pseudomonas spp.: diversity, activity, biosynthesis, and regulation. Mol. Plant Microbe Interact. 19, 699-710.

Rajasekaran, K., Cary, J., Jaynes, J. and Montesinos, E. (2012) Small Wonders: Peptides for Disease Control. American Chemical Society: Oxford University Press.

Rasche, S., Martin, A., Holzem, A., Fischer, R., Schinkel, H. and Schillberg, S. (2011) One-step protein purification: Use of a novel epitope tag for highly efficient detection and purification of recombinant proteins. Open Biotechnol. J. 5, 1-6.

Sambrook, J. and Russell, D. (2001) Molecular Cloning: A Laboratory Manual, 3rd ed. Cold Spring Harbor: Cold Spring Harbor Laboratory Press.

Tincu, J.A. and Taylor, S.W. (2004) Antimicrobial peptides from marine invertebrates. Antimicrob. Agents Chemother. 48, 3645-3654.

Toke, O. (2005) Antimicrobial peptides: new candidates in the fight against bacterial infections. Biopolymers, 80, 717-735.
Torrent, M., Llompart, B., Lasserre-Ramassamy, S., Llop-Tous, I., Bastida, M., Marzabal, P., Westerholm-Parvinen, A., Saloheimo, M., Heifetz, P.B. and Ludevid, M.D. (2009) Eukaryotic protein production in designed storage organelles. BMC Biol. 7, 5.

Torrent, M., Pulido, D., Rivas, L. and Andreu, D. (2012) Antimicrobial peptide action on parasites. Curr. Drug Targets, 13, 1138-1147.

Tossi, A., Sandri, L. and Giangaspero, A. (2000) Amphipathic, alpha-helical antimicrobial peptides. Biopolymers, 55, 4-30.

Truernit, E. and Haseloff, J. (2008) A simple way to identify non-viable cells within living plant tissue using confocal microscopy. Plant Methods, 4, 15.

Twyman, R.M., Stoger, E., Schillberg, S., Christou, P. and Fischer, R. (2003) Molecular farming in plants: host systems and expression technology. Trends Biotechnol. 21, 570-578.

Vandesompele, J., De Preter, K., Pattyn, F., Poppe, B., Van Roy, N., De Paepe, A. and Speleman, F. (2002) Accurate normalization of real-time quantitative RT-PCR data by geometric averaging of multiple internal control genes. Genome biology, 3, Research 0034.

Vaquero, C., Sack, M., Chandler, J., Drossard, J., Schuster, F., Monecke, M. Schillberg, S. and Fischer, R. (1999) Transient expression of a tumor-specific single-chain fragment and a chimeric antibody in tobacco leaves. Proc. Natl Acad. Sci. USA, 96, 11128-11133.

Yeaman, M.R. and Yount, N.Y. (2003) Mechanisms of antimicrobial peptide action and resistance. Pharmacol. Rev. 55, 27-55.

Yount, N.Y. and Yeaman, M.R. (2005) Immunocontinuum: perspectives in antimicrobial peptide mechanisms of action and resistance. Protein Pept. Lett. 12, 49-67.

Zasloff, M. (2002) Antimicrobial peptides of multicellular organisms. Nature, 415, 389-395.

\section{Supporting information}

Additional Supporting information may be found in the online version of this article:

Figure S1 Transgene mRNA expression levels (relative to actin) in the leaves of transgenic rice plants grown in vitro, as assessed by quantitative real-time RT-PCR.

Figure S2 Phytotoxicity of chemically synthesized BP100 derivatives as determined using $N$. benthamiana leaf inoculation (dark grey) and rice germination (light grey) assays (Nadal et al., 2012). 